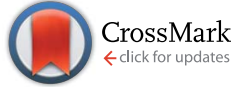

Cite this: J. Mater. Chem. B, 2015, 3, 1142

Received 7th November 2014

Accepted 27th November 2014

DOI: $10.1039 / c 4 t b 01840 k$

www.rsc.org/MaterialsB

\section{Angiogenic effects of ionic dissolution products released from a boron-doped 45S5 bioactive glass}

\begin{abstract}
Luis A. Haro Durand, ${ }^{\text {ab }}$ Gabriela E. Vargas, ${ }^{c}$ Nélida M. Romero, ${ }^{c}$ Rosa Vera-Mesones, ${ }^{c}$ José M. Porto-López, ${ }^{d}$ Aldo R. Boccaccini, e María P. Zago, ${ }^{f}$ Alberto Baldi ${ }^{b}$ and Alejandro Gorustovich*a

In regenerative medicine of vascularized tissues, there is a great interest in the use of biomaterials that are able to stimulate angiogenesis, a process necessary for rapid revascularization to allow the transport and exchange of oxygen, nutrients, growth factors and cells that take part in tissue repair and/or regeneration. An increasing number of publications have shown that bioactive glasses stimulate angiogenesis. Because it has been established that boron (B) may play a role in angiogenesis, the aim of this study was to assess the in vivo angiogenic effects of the ionic dissolution products that from a bioactive glass (BG) in the $45 \mathrm{~S} 5$ system doped with $2 \mathrm{wt} \% \mathrm{~B}_{2} \mathrm{O}_{3}$ (45S5.2B). The pro-angiogenic capacity of $45 \mathrm{~S} 5.2 \mathrm{~B}$ BG was assessed on the vasculature of the embryonic quail chorioallantoic membrane (CAM). Ionic dissolution products from 45S5.2B BG increased angiogenesis. This is quantitatively evidenced by the greater expression of integrin $\alpha_{v} \beta_{3}$ and higher vascular density in the embryonic quail CAM. The response observed at 2 and 5 days post-treatment was equivalent to that achieved by applying $10 \mu \mathrm{g}$ $\mathrm{mL}^{-1}$ of basic fibroblast growth factor. These results show that the ionic dissolution products released from the bioactive glass 45S5.2B stimulate angiogenesis in vivo. The effects observed are attributed to the presence the ionic dissolution products, which contained $160 \pm 10 \mu \mathrm{M}$ borate.
\end{abstract}

\section{Introduction}

In regenerative medicine of vascularized tissues (such as bone and heart muscle), there is great interest in the use of biomaterials that are able to stimulate angiogenesis, a process necessary to achieve a rapid revascularization to allow the transport and exchange of oxygen, nutrients, growth factors and cells involved in tissue repair and regeneration..$^{1-4}$ Biomaterials have been categorized as first-, second- and third-generation biomaterials, according to the biological behavior they are able to trigger. First-generation materials show inert (non-bioactive) behavior, whereas second- and third-generation materials show bioactive properties. ${ }^{5}$ Non-bioactive materials determine the formation of a capsule of non-adherent fibrous connective

${ }^{a}$ Interdisciplinary Materials Group-IESIING-UCASAL, INTECIN UBA-CONICET, Campus Castañares, A4400EDD, Salta, Argentina. E-mail: agorustovich@conicet. gov. ar; Tel: +54-387-426-8522

${ }^{b}$ Department of Pathology and Molecular Pharmacology, IByME-CONICET, C1428ADN, Buenos Aires, Argentina

${ }^{c}$ Department of Developmental Biology, National University of Salta, A4408FVY, Salta, Argentina

${ }^{d}$ Research Institute for Materials Science and Technology, INTEMA-CONICET, B7608FDQ, Mar del Plata, Argentina

${ }^{e}$ Institute of Biomaterials, Department of Materials Science and Engineering, University of Erlangen-Nuremberg, 91058 Erlangen, Germany

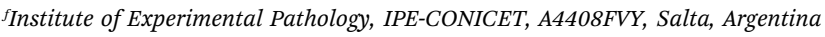

tissue around the implant material, whereas bioactive materials have been defined as those able to trigger a specific biological response at the level of the interface that determines the integration of the material to the tissues. ${ }^{5}$ The new generation of bioactive materials, known as third-generation materials, comprises all those bioreabsorbable and/or biodegradable materials able to stimulate specific cellular responses at the molecular level as a result of the release of ions. ${ }^{5}$ A growing number of publications have shown experimental evidence about the biological effects of the ionic dissolution products released from bioceramic materials. ${ }^{6-10}$ Within this context, it is important to mention the progress made with bioactive glasses (BGs). ${ }^{6,8-10}$ The most widely used BGs are amorphous solids based on a silicate matrix. ${ }^{\mathbf{1 1 - 1 4}}$ Although a growing number of publications have shown that the BGs in the 45S5 system (in weight\%: 45\% $\mathrm{SiO}_{2}, 24.5 \% \mathrm{Na}_{2} \mathrm{O}, 24.5 \% \mathrm{CaO}, 6 \% \mathrm{P}_{2} \mathrm{O}_{5}$ (Bioglass $\left.{ }^{\circledR}\right)$ ) or related compositions stimulate angiogenesis, ${ }^{\mathbf{1 5}}$ the specific mechanisms that accelerate neovascularization in the presence of the ions released by the dissolution of BGs of different chemical composition have not yet been elucidated.

The rationale for incorporating boron (B) to BGs as biomaterials for osseous implants and bone tissue-engineering scaffolds is the emerging scientific evidence that B has well-defined biological effects such as stimulation of bone healing in vivo and angiogenesis in vitro. ${ }^{16-18}$ Noteworthy, Brown et al. ${ }^{19}$ reported that with increasing $\mathrm{B}_{2} \mathrm{O}_{3}$ content, greater than $\sim 1 / 3$ of the 
$\mathrm{SiO}_{2}$ in the 45S5 BG system, the glasses produced a greater inhibition of cell proliferation, particularly in static culture conditions.

We have previously demonstrated that microparticles of a boron-modified 45S5 composition, containing 2 wt $\% \quad \mathrm{~B}_{2} \mathrm{O}_{3}$ (45S5.2B), enhance bone formation more than $45 \mathrm{~S} 5$ glass particles when implanted into the intramedullary canal of rat tibiae. ${ }^{16}$ Moreover, human umbilical vein endothelial cells (HUVECs) possess greater proliferative and migratory response, greater tubule formation capacity in vitro and greater secretion of pro-angiogenic cytokines (IL-6 and bFGF) when stimulated with the dissolution products from 45S5.2B BG. ${ }^{18}$ Therefore, the aim of the present study was to assess the in vivo angiogenic effects of the ionic dissolution products released from 45S5.2B BG prepared by partially replacing the $\mathrm{SiO}_{2}$ content of $45 \mathrm{~S} 5 \mathrm{BG}$ with $2 \mathrm{wt} \%$ of $\mathrm{B}_{2} \mathrm{O}_{3}$.

\section{Materials and methods}

\subsection{Obtention and characterization of ionic dissolution products from bioactive glasses}

We used the following bioactive glasses (BGs): 45S5 and 45S5 doped with B (45S5.2B), previously developed in our laboratory. ${ }^{16,18}$ The base composition selected for the preparation of these BGs complies with the following characteristics: (a) it is bioactive and (b) it belongs to the $\mathrm{SiO}_{2}-\mathrm{CaO}-\mathrm{Na}_{2} \mathrm{O}-\mathrm{P}_{2} \mathrm{O}_{5}$ system. The BGs were prepared from the following raw materials: $\mathrm{SiO}_{2}$, $\mathrm{CaCO}_{3}, \mathrm{Na}_{2} \mathrm{CO}_{3}, \mathrm{CaHPO}_{4} \cdot 2 \mathrm{H}_{2} \mathrm{O}$, and $\mathrm{B}_{4} \mathrm{Na}_{2} \mathrm{O}_{7} \cdot 10 \mathrm{H}_{2} \mathrm{O}$. The raw materials were mixed in the relationship necessary to obtain the desired composition in a base $45 \mathrm{~S} 5$ BG containing $45 \%$ (in weight $\%$ ) $\mathrm{SiO}_{2}, 24.5 \% \mathrm{Na}_{2} \mathrm{O}, 24.5 \% \mathrm{CaO}$, and $6 \% \mathrm{P}_{2} \mathrm{O}_{5}$, and to which $2 \%$ of $\mathrm{B}_{2} \mathrm{O}_{3}$ (45S5.2B) was added to partially replace $\mathrm{SiO}_{2} \cdot{ }^{16,18}$ Mixing was carried out in a platinum crucible at $1350{ }^{\circ} \mathrm{C}$ using an electric oven (Carbolite RHF 17/6S, Carbolite Ltd, England) holding the temperature for $3 \mathrm{~h}$ to allow the fusion of the components and the homogenization of the glass. The molten glass was quenched on graphite plates to allow fast cooling, and thus preventing its crystallization. Considering that the use of particles smaller than or equal to $5 \mu \mathrm{m}$ allows a fast in vitro release of ions from $45 \mathrm{~S} 5 \mathrm{BG},{ }^{20}$ in the present study, the ionic dissolution products were obtained by incubating 1 $\mathrm{mg} \mathrm{mL} \mathrm{m}^{-1}$ of $45 \mathrm{~S} 5 \mathrm{BG}$ or $45 \mathrm{~S} 5.2 \mathrm{~B} \mathrm{BG}$ particles $(<5 \mu \mathrm{m})$ in a Ca and $\mathrm{Mg}$ free Hanks balanced salt solution (HBSS) at $37{ }^{\circ} \mathrm{C}$ on an orbital shaker for $24 \mathrm{~h}$. The ionic dissolution products were buffered ( $\mathrm{pH} 7$ ), and then filtered through a $0.22 \mu \mathrm{m}$ filter to be used in different experiments. B, Si, P, Ca, and $\mathrm{Na}$ ions leached from the BGs were determined using inductively coupled plasma-optical emission spectrometry (ICP-OES; Optima 3100 XL, Perkin-Elmer, Wellsley, MA, USA) (Table 1).

\subsection{Evaluation of the angiogenic response}

The angiogenic effects were evaluated on the vasculature of the chorioallantoic membrane (CAM) of quail (Coturnix coturnix japonica) embryos according to the method described by Parsons-Wingerter et al. ${ }^{21}$ Quail egg culture and experimental methods were approved by the institutional ethics committee of the School of Dentistry, University of Buenos Aires, Argentina. Humane care of the animals were carried out according to the Guide for the Care and Use of Laboratory Animals, National Research Council (USA), 2010.

Fertilized eggs were incubated in ovo for 3 days at $38{ }^{\circ} \mathrm{C}$ and $60 \%$ relative humidity. Subsequently, their content was poured in six-well culture plates. After 7 days of total incubation, either $0.5 \mathrm{~mL}$ HBSS enriched with ionic dissolution products (HBSS + 45S5; HBSS + 45S5.2B) or $0.5 \mathrm{~mL}$ HBSS enriched with ionic dissolution products supplemented with $10 \mu \mathrm{g} \mathrm{mL} \mathrm{m}^{-1}$ of basic fibroblast growth factor (bFGF) (HBSS + 45S5/bFGF; HBSS + 45S5.2B/bFGF) was added onto the CAMs. HBSS supplemented with bFGF (HBSS + bFGF) was used as a positive control, whereas HBSS with no ionic products or bFGF was used as a negative control. We also evaluated the effect of HBSS enriched with the final borate concentrations of $5 \mu \mathrm{M}, 50 \mu \mathrm{M}$ and $150 \mu \mathrm{M}$. Each experiment included ten embryos per group and was repeated twice. At 2 and 5 days post-treatment, embryos were killed by freezing $\left(-20{ }^{\circ} \mathrm{C}\right)$, fixed in $10 \%$ formalin buffer and the external morphological characters described by Ainsworth et al. ${ }^{22}$ evaluated with the aim to determine the embryonic stage were reached. CAMs were then processed for further analysis according to the technical protocol for each of the procedures described below:

(a) Evaluation of the expression of integrin $\alpha_{v} \beta_{3}$ as an indicator parameter of angiogenesis

ELISA. An ELISA was conducted to determine the endogenous levels of integrin $\alpha_{v} \beta_{3}$. At 2 days post-treatment, CAMs were homogenized in PBS, and $10 \mu \mathrm{g}$ of total protein (as determined by the Bradford assay) was used to sensitize 96-well plates, in triplicate. The plates were dried at $37{ }^{\circ} \mathrm{C}$, blocked with $5 \%$ BSA in PBS, then incubated with the anti- $\alpha_{\mathrm{v}} \beta_{3}$ monoclonal antibody (Millipore LM609 $1 \mu \mathrm{g} \mathrm{mL}{ }^{-1}$ ), washed three times with PBS and incubated with rabbit anti-mouse IgG antibody conjugated to peroxidase (Sigma A9044-2ML), which was revealed with 3,3',5,5'-tetramethyl-benzidine (Sigma T4444). The optical density was determined in an ELISA reader at $492 \mathrm{~nm}$.

Polyacrylamide gel electrophoresis. To analyze the expression levels of the $\beta_{3}$ subunit of integrin $\alpha_{v} \beta_{3}$, CAMs were homogenized in $1 \mathrm{~mL}$ of radio-immunoprecipitation assay lysis buffer [100 mM Tris pH 7.5, $150 \mathrm{mM}$ NaCl, $1 \mathrm{mM}$ ethylenediaminetetraacetic acid 1\% deoxycholic acid, $1 \%$ Triton $\mathrm{X}$ $100,0.1 \%$ sodium dodecyl sulfate (SDS), $2 \mathrm{mM}$ phenylmethanesulfonyl fluoride and the phosphatase inhibitors NaF $(500 \mathrm{mM})$ and vanadate $(1 \mathrm{mM})]$ and centrifuged for $15 \mathrm{~min}$ at $15000 \mathrm{~g}$, and the amount of total protein was determined by the Bradford assay. Equivalent amounts of protein were heated (at $90{ }^{\circ} \mathrm{C}$ for $5 \mathrm{~min}$ ) in loading buffer (50 mM Tris-HCl, pH 6.6, 2\% SDS, $10 \%$ glycerol and $0.05 \%$ bromophenol blue) and loaded in an $8 \%$ mini-polyacrylamide gel. Electrophoresis was performed in $0.025 \mathrm{M}$ Tris buffer, $0.192 \mathrm{M}$ glycine, $0.1 \%$ SDS, $\mathrm{pH} 8.3$ at a constant current of $35 \mathrm{~mA}$ per gel in an electrophoresis cell (Mini-Protean ${ }^{\circledR}$ II, Bio-Rad).

Western Blot. The polyacrylamide gels were balanced in transfer buffer (25 mM Tris-HCl, pH 8.3, $150 \mathrm{mM}$ glycine, 20\% (v/v) methanol) for $15 \mathrm{~min}$ and the proteins transferred to a nitrocellulose membrane (Hybond, Amersham Biosciences, 
Table 1 Elemental concentration determined by inductively coupled plasma-optical emission spectrometry (ICP-OES) (mean \pm SD) ${ }^{a}$

\begin{tabular}{llllll}
\hline & $\mathrm{B}(\mu \mathrm{M})$ & $\mathrm{Si}\left(\mu \mathrm{g} \mathrm{mL}^{-1}\right)$ & $\mathrm{P}\left(\mu \mathrm{g} \mathrm{mL} L^{-1}\right)$ & $\mathrm{Ca}\left(\mu \mathrm{g} \mathrm{mL} L^{-1}\right)$ & $\mathrm{Na}\left(\mu \mathrm{g} \mathrm{mL}{ }^{-1}\right)$ \\
\hline HBSS & Bld & Bld & Bld & $20 \pm 0.6$ & Bld \\
HBSS + 45S5 & Bld & Bld & $4.5 \pm 0.08$ & $12.8 \pm 0.3$ & $3451 \pm 51$ \\
HBSS + 45S5.2B & $160 \pm 10$ & $4.4 \pm 0.11$ & $12 \pm 0.3$
\end{tabular}

${ }^{a}$ SD: standard deviation; Bld: below the limit of detection.

$0.45 \mu \mathrm{m}$ RPN303D) at $100 \mathrm{~V}$ for $1 \mathrm{~h}$ at $4{ }^{\circ} \mathrm{C}$ in an electrophoretic transfer cell (Mini-Trans-Blot, Bio-Rad). Proteins were then stained in a solution with $0.2 \%$ Ponceau $S$ in $0.5 \%$ acetic acid to visualize the total proteins and verify the effectiveness of the transfer in all lanes. The membranes were blocked overnight with 5\% skim milk powder and $0.05 \%$ Tween-20 in PBS (PBS-LT) at $4{ }^{\circ} \mathrm{C}$, washed three times with $0.05 \%$ Tween-20 in PBS and incubated for $24 \mathrm{~h}$ with the anti- $\beta_{3}$ IgG polyclonal primary antibody, which is produced in rabbit, in a $1: 500$ dilution (Santa Cruz Biotechnology sc-14009) in PBS-L-T at $4{ }^{\circ} \mathrm{C}$. CAMs were then washed and detection was carried out by incubating for $2 \mathrm{~h}$ with anti-rabbit IgG secondary antibody conjugated to horseradish peroxidase in a 1:2000 dilution (Santa Cruz Biotechnology sc-2004) in blocking buffer at room temperature. CAMs were then washed and incubated for $1 \mathrm{~min}$ with a chemiluminescent substrate for peroxidase (ECL ${ }^{\mathrm{TM}}$, Amersham Biosciences). The result was visualized by autoradiography of the chemiluminescent reaction.

(b) Quantification of angiogenesis. CAMs corresponding to 2 and 5 days post-treatment were fixed in situ in 4\% paraformaldehyde $/ 2 \%$ glutaraldehyde in PBS. After 3 days, CAMs were resected and analyzed under a stereomicroscope maintained at one focal plane. Images were taken from three different areas of the CAMs enclosed with Whatman filter paper discs ( $5 \mathrm{~mm}$ in diameter). The vascular density was evaluated with Image J according to the method described by Brooks et al. ${ }^{23}$ which consists in quantifying the number of blood vessel branch points in the area of the CAM $\left(\sim 20 \mathrm{~mm}^{2}\right)$ confined to each disk.

\section{Statistical analysis}

The results were statistically analyzed assuming $\alpha=0.05$ and $\beta$ $=0.10$. For all the data, we calculated the mean \pm standard deviation. The results were analyzed by the analysis of variance (ANOVA) and Bonferroni was used as a post hoc test.

\section{Results}

\subsection{Evaluation of the expression of integrin $\alpha_{v} \beta_{3}$}

The ELISA showed that the levels of expression of integrin $\alpha_{v} \beta_{3}$ in CAMs 2 days after the treatment with ionic dissolution products from the bioactive glass 45S5.2B were 2.5-3-fold higher than in those treated with HBSS (Fig. 1). In addition, the Western blot showed greater expression of the $\beta_{3}$ subunit of integrin $\alpha_{v} \beta_{3}$ (Fig. 2).

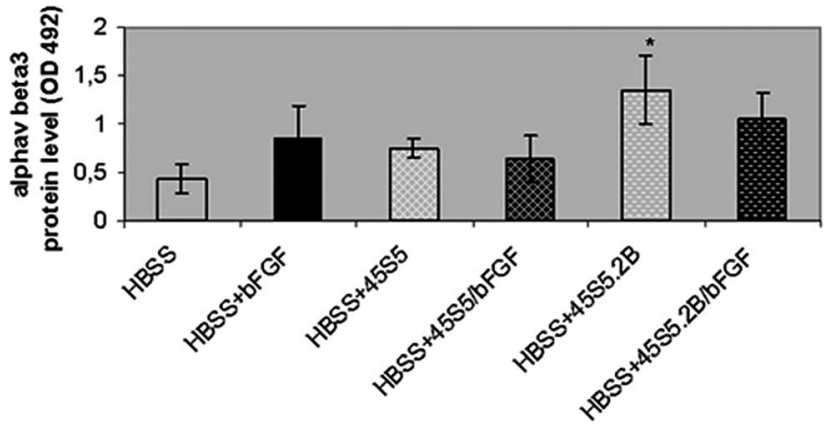

Fig. 1 Endogenous expression levels of integrin $\alpha_{v} \beta_{3}$ in CAMs at two days post-treatment $(* p<0.05)$. OD: optical density.

\subsection{Quantification of the angiogenic response}

Two days after the treatment, in comparison to the negative control (HBSS), there were no statistically significant differences in the vascular density of CAMs treated with HBSS $+45 \mathrm{~S} 5$ or HBSS + 45S5/bFGF. In contrast, both the CAMs treated with HBSS +45 S5.2B and those treated with HBSS $+45 \mathrm{~S} 5.2 \mathrm{~B} / \mathrm{bFGF}$ showed higher vascular density, $58 \%$ and $84 \%$. The response observed was equivalent to that achieved by applying $10 \mu \mathrm{g} \mathrm{mL} \mathrm{m}^{-1}$ of basic fibroblast growth factor (HBSS + bFGF) (Fig. 3 and 4).

Five days after the treatment, in comparison to the negative control (HBSS), we found no statistically significant differences in the vascular density of CAMs treated with HBSS + 45S5 or HBSS + 45S5/bFGF. In contrast, both the CAMs treated with HBSS + 45S5.2B and those treated with HBSS + 45S5.2B/bFGF showed higher vascular density, $30 \%$ and $73 \%$, respectively, this being the response equivalent to that observed after the treatment with HBSS + bFGF (Fig. 5 and 6).

The effect of HBSS with different borate concentrations was evaluated to establish whether the presence of borate is responsible for the higher angiogenic activity observed in the CAMs treated with HBSS enriched with the dissolution products from the bioactive glass 45S5.2B. The results showed that relative to the control (HBSS), all the borate concentrations used $(5,50$, and $150 \mu \mathrm{M})$ had pro-angiogenic capacity in vivo (Fig. 7), evidencing greater vascular density in CAMs corresponding to 5 days post-treatment. It is important to point out that no statistically significant differences were found in the response achieved with the application of HBSS containing 50 or $150 \mu \mathrm{M}$ borate at 2 or 5 days post-treatment (Fig. 8). 


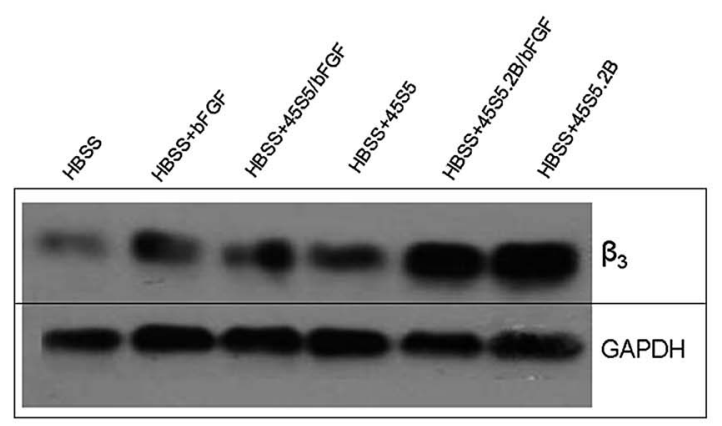

a

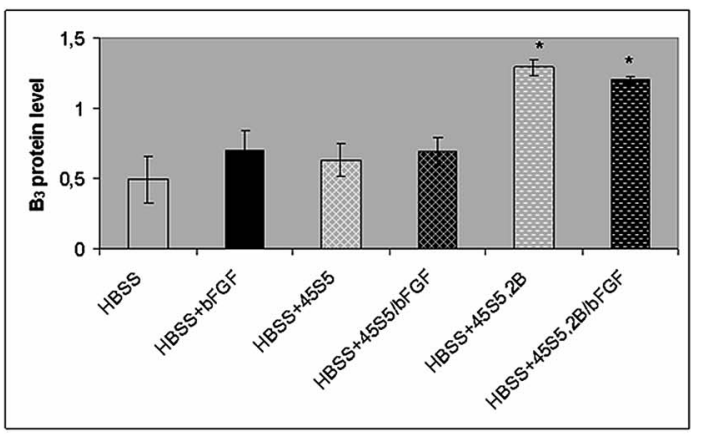

b

Fig. 2 Western blot (a) and relative expression of the $\beta_{3}$ subunit of integrin $\alpha_{v} \beta_{3}$ (b). ( ${ }^{*} p<0.05$ with respect to HBSS and HBSS + bFGF).
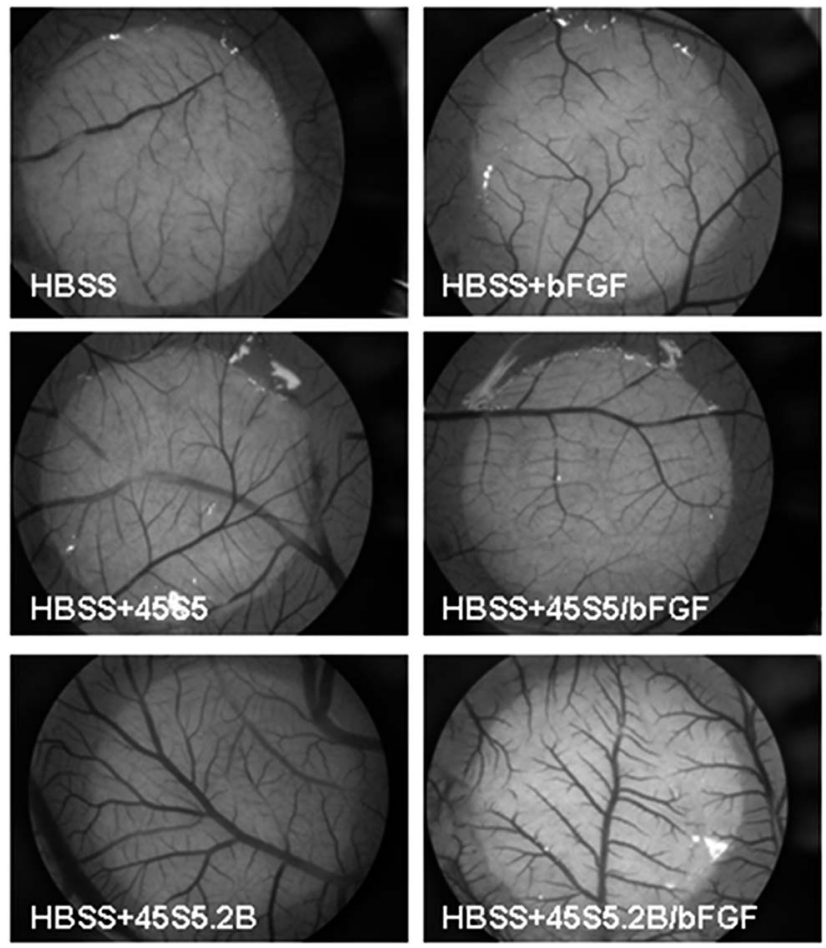

Fig. 3 Angiogenic response of CAMs at two days post-treatment Original magnification $\times 20$

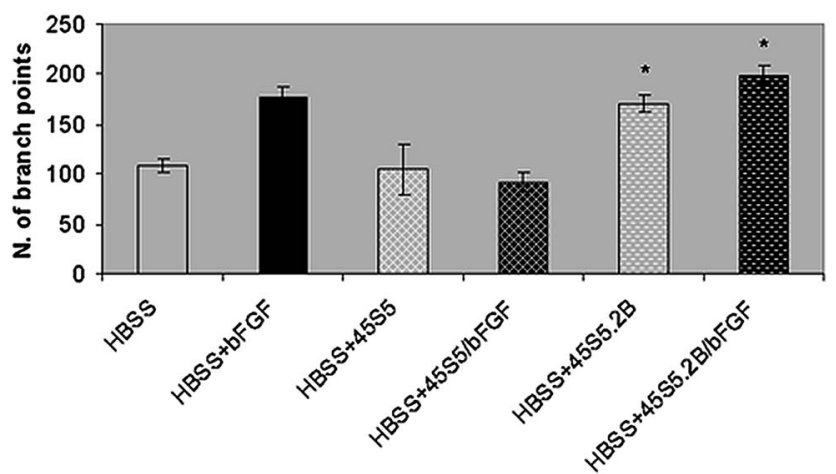

Fig. 4 Number of blood vessel branch points at two days posttreatment $\left({ }^{*} p<0.05\right.$ with respect to HBSS).
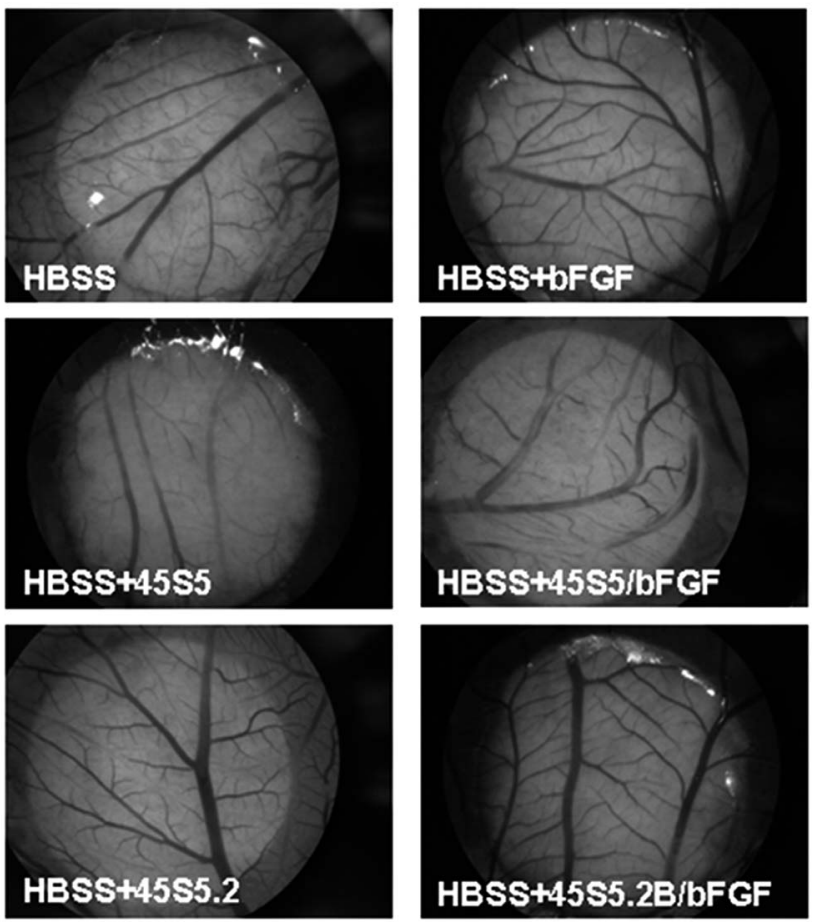

Fig. 5 Angiogenic response of CAMs at five days post-treatment. Original magnification $\times 20$.

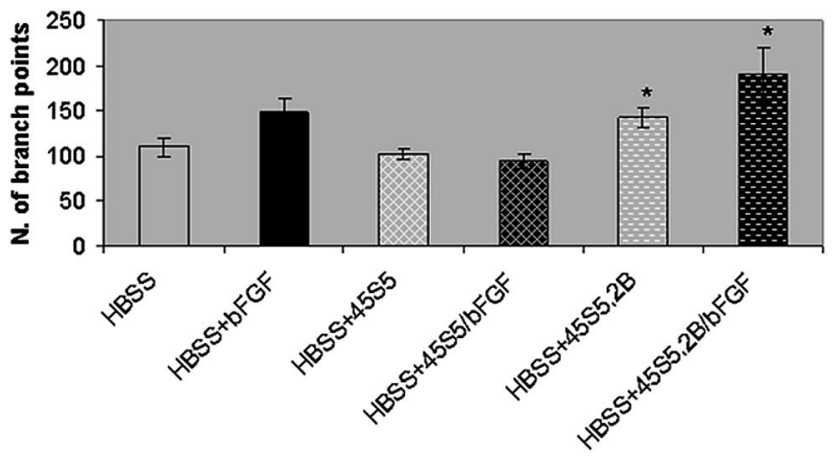

Fig. 6 Number of blood vessel branch points at five days post-treatment ( ${ }^{*} p<0.05$ with respect to HBSS). 

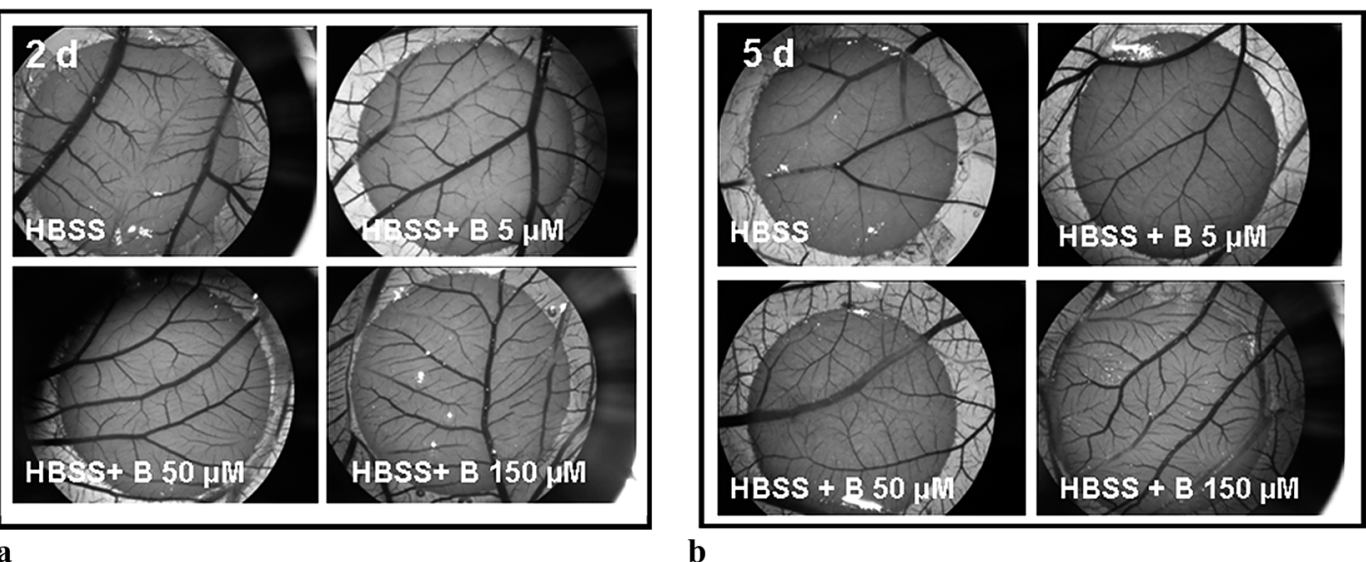

b

Fig. 7 Angiogenic response of CAMs (a) at two and (b) five days post-treatment with HBSS with different borate concentrations. Original magnification $\times 20$.

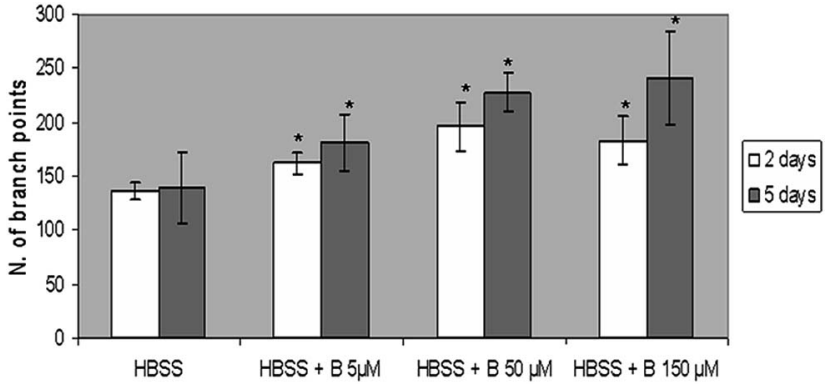

Fig. 8 Number of blood vessel branch points at two and five days post-treatment with HBSS with different borate concentrations $\left({ }^{*} p<\right.$ 0.05 with respect to HBSS)

\section{Discussion}

The chorioallantoic membrane (CAM) of quail embryos has been widely used as an in vivo experimental model to evaluate angiogenesis and anti-angiogenesis in response to different factors. ${ }^{21,24-27}$ Although in the present study the ionic dissolution products of the bioactive glass (BG) $45 \mathrm{~S} 5$ showed no angiogenic capacity, they did not affect the normal development of the vasculature of embryonic quail CAMs. This observation is in line with previous studies, ${ }^{28,29}$ which found that 45S5 Bioglass ${ }^{\circledR}$-based scaffolds were unable to induce an angiogenic response in the chick embryo CAM. These results are probably associated with an insufficient ions release from the scaffolds due to the smaller contact area of the scaffolds to the CAM. In contrast, Arkudas et al. $^{30}$ were able to show an increased neovascularization of a particulated sintered $45 \mathrm{~S} 5$ Bioglass ${ }^{\circledR}$ matrix in the rat arteriovenous loop model.

Recent publications indicate that silicon ( $\mathrm{Si}$ ) ions $(0.7-1.8 \mu \mathrm{g}$ $\mathrm{mL}^{-1}$ ) released from silicate-based ceramic materials stimulate the in vitro secretion of pro-angiogenic growth factors, proliferation of endothelial cells and promote angiogenesis in vivo. ${ }^{31,32}$ The ionic dissolution products used in the present work have insufficient concentration of Si given that they were obtained using HBSS containing glucose $\left(1 \mathrm{~g} \mathrm{~L}^{-1}\right)$, an agent known to delay the dissolution of BGs..$^{33}$ However, our preliminary degradation studies in HBSS for $72 \mathrm{~h}$ revealed that Si concentrations leached from particles $(<5 \mu \mathrm{m})$ of $45 \mathrm{~S} 5 \mathrm{BG}$ and 45S5.2B BG were $18.79 \mu \mathrm{g} \mathrm{mL} \mathrm{m}^{-1}$ and $17.82 \mu \mathrm{g} \mathrm{mL} \mathrm{m}^{-1}$, respectively, while the amount of borate ions released from the 45S5.2B BG particles was about $20 \mu \mathrm{M}$. The combination of Si ions with other ions including B released from bioactive glasses might have synergistic effect and further enhance the angiogenesis. ${ }^{10}$

The use of ionic dissolution products released from the 45S5.2B BG showed an increase in angiogenesis and this is quantitatively evidenced by the greater expression of integrin $\alpha_{v} \beta_{3}$ and the greater vascular density in CAMs treated with HBSS +45 S5.2B or HBSS + 45S5.2B supplemented with basic fibroblast growth factor (bFGF).

One of the major concerns regarding in vivo delivery of bioactive ions from biomaterials is whether the released amount of ions is within the therapeutic level to have any positive effect. ${ }^{7,8,10}$ HBSS + 45S5.2B contains $160 \pm 10 \mu \mathrm{M}$ borate, a concentration that is below the reference values with which cytotoxic effects become apparent, ${ }^{34}$ and that represents approximately ten times the normal concentration of $\mathrm{B}$ in human plasma $(13 \pm 3 \mu \mathrm{M}))^{34,35}$

Considering also that HBSS with different borate concentrations $(5,50$, and $150 \mu \mathrm{M})$ demonstrated pro-angiogenic ability in CAMs, it can be assumed that the presence of borate in the ionic dissolution products from 45S5.2B BG is the factor responsible for the greater angiogenic activity. It has been demonstrated that $\mathrm{B}$ in the form of $\mathrm{H}_{3} \mathrm{BO}_{3}$ potently activates the mitogen-activated protein kinase (MAPK) signaling pathway to markedly increase cell proliferation and growth at low concentrations and inhibits these activities at high concentrations. ${ }^{34}$ Accordingly, we have previously shown that the ionic dissolution products from 45S5.2B BG stimulated human umbilical vein endothelial cells (HUVECs) proliferation and migration by phosphorylation of extracellular signal-related kinase (ERK) 1/2, focal adhesion kinase (FAK) and p38 protein. It was also shown that ionic dissolution products from 45S5.2B BG could enhance 
in vitro HUVECs tubule formation and secretion of interleukin 6 (IL6) and bFGF. ${ }^{18}$ The effects observed in the present study are probably due to the fact that borate stimulates the secretion of cytokines and/or growth factors with pro-angiogenic activity and the proliferation of endothelial cells of the CAM vasculature, as evidenced by the higher expression of integrin $\alpha_{v} \beta_{3}$. The process of angiogenesis involves coordinated endothelial cell proliferation, migration and tube formation. This process is induced by vascular growth factors in coordination with extracellular matrix interacting molecules such as integrins. Among integrins, $\alpha_{v} \beta_{3}$ heterodimer is expressed at low levels on quiescent endothelial cells in vivo, but is significantly up-regulated on proliferating endothelial cells during angiogenesis and vascular remodeling. ${ }^{36,37}$

It is important to note that the response observed at 2 and 5 days post-treatment with HBSS $+45 \mathrm{~S} 5.2 \mathrm{~B}$ was equivalent to that after the application of $10 \mu \mathrm{g} \mathrm{mL} \mathrm{mL}^{-1}$ of bFGF. In this context, the ionic dissolution products from 45S5.2B BG may act as inexpensive inorganic angiogenic agents providing a convenient alternative to the application of conventional angiogenic growth factors. Concerns about the toxicity of B to cells in vivo have been alleviated by results showing that borate ions released from bioactive glasses are non-toxic in small animals. Recently, Lin et al. ${ }^{38}$ showed that high amounts (up to $1120 \mathrm{mg}$ per animal) of 13-93B3 borate glass microfibers containing $53 \mathrm{wt} \%$ of $\mathrm{B}_{2} \mathrm{O}_{3}$ implanted subcutaneously in rats can be safely used with no systemic toxicity. Overall, it can be expected that the controlled and localized release of borate ions from 45S5.2B BG could represent a promising alternative therapeutic strategy to achieve neovascularization in regenerative medicine and tissue engineering of vascularized tissues, such as bone.

\section{Conclusions}

The results of this study demonstrate that the ionic dissolution products released from microparticles of the bioactive glass 45S5.2B stimulate angiogenesis in vivo. We attribute these effects to the presence of borate in the ionic dissolution products.

\section{Disclosure statement}

No competing financial interests exist.

\section{Acknowledgements}

We thank Dr Forrest H. Nielsen (US Department of Agriculture, Agricultural Research Service, USDA, ARS Grand Forks Human Nutrition Research Center) for the inductively coupled plasmaoptical emission spectrometry (ICP-OES) analysis. This study was funded by the National University of Salta and Catholic University of Salta, Argentina (grants CIUNSa 2021 and UCASAL 57211).

\section{References}

1 M. Lovett, K. Lee, A. Edwards and D. L. Kaplan, Tissue Eng., Part B, 2009, 15, 353-370.

2 H. Bae, A. S. Puranik, R. Gauvin, F. Edalat, B. Carrillo-Conde, N. A. Peppas and A. Khademhosseini, Sci. Transl. Med., 2012, 4, 160ps23.

3 R. S. Roy, B. Roy and S. Sengupta, Nanotechnology, 2011, 22, 494004.

4 A. Aguirre, A. González, M. Navarro, O. Castaño, J. A. Planell and E. Engel, Eur. Cells Mater., 2012, 24, 90-106.

5 L. L. Hench and J. M. Polak, Science, 2002, 295, 1014-1017. 6 A. Hoppe, N. S. Güldal and A. R. Boccaccini, Biomaterials, 2011, 32, 2757-2774.

7 S. Bose, G. Fielding, S. Tarafder and A. Bandyopadhyay, Trends Biotechnol., 2013, 31, 594-605.

8 A. Hoppe, V. Mouriño and A. R. Boccaccini, Biomater. Sci., 2013, 1, 254-256.

9 N. J. Lakhkar, I. H. Lee, H. W. Kim, V. Salih, I. B. Wall and J. C. Knowles, Adv. Drug Delivery Rev., 2013, 65, 405-420.

10 C. Wu and J. Chang, J. Controlled Release, 2014, 193, 282-295. 11 D. Arcos and M. Vallet-Regí, Acta Biomater., 2010, 6, 28742888.

12 A. N. Cormack and A. Tilocca, Philos. Trans. R. Soc., A, 2012, 370, 1271-1280.

13 C. Wu and J. Chang, Interface Focus, 2012, 2, 292-306.

14 J. R. Jones, Acta Biomater., 2013, 9, 4457-4486.

15 A. Gorustovich, J. A. Roether and A. R. Boccaccini, Tissue Eng., Part B, 2010, 16, 199-207.

16 A. Gorustovich, J. M. Porto López, M. B. Guglielmotti and R. L. Cabrini, Biomed. Mater., 2006, 1, 100-105.

17 A. Gorustovich, T. Steimetz, F. H. Nielsen and M. B. Guglielmotti, Anat. Rec., 2008, 291, 441-447.

18 L. A. Haro Durand, A. Góngora, J. M. Porto López, A. R. Boccaccini, M. P. Zago, A. Baldi and A. Gorustovich, J. Mater. Chem. B, 2014, 2, 7620-7630.

19 R. F. Brown, M. N. Rahaman, A. B. Dwilewicz, W. Huang, D. E. Day, Y. Li and B. S. Bal, J. Biomed. Mater. Res., Part A, 2009, 88, 392-400.

20 P. Sepulveda, J. R. Jones and L. L. Hench, J. Biomed. Mater. Res., 2002, 61, 301-311.

21 P. Parsons-Wingerter, B. Lwai, M. C. Yang, K. E. Elliot, A. Milaninia, A. Redlitz, J. I. Clark and E. H. Sage, Microvasc. Res., 1998, 55, 201-214.

22 S. J. Ainsworth, R. L. Stanley and D. J. Evans, J. Anat., 2010, 216, 3-15.

23 P. C. Brooks, A. M. Montgomery and D. A. Cheresh, Methods Mol. Biol., 1999, 129, 257-269.

24 S. J. Oh, M. M. Jeltsch, R. Birkenhäger, J. E. McCarthy, H. A. Weich, B. Christ, K. Alitalo and J. Wilting, Dev. Biol., 1997, 188, 96-109.

25 P. Parsons-Wingerter, K. E. Elliott, J. I. Clark and A. G. Farr, Arterioscler., Thromb., Vasc. Biol., 2000, 20, 1250-1256.

26 M. González-Iriarte, R. Carmona, J. M. Pérez-Pomares, D. Macías, M. A. Medina, A. R. Quesada and R. MuñozChápuli, Angiogenesis, 2003, 6, 251-254. 
27 P. Lazarovici, A. Gazit, I. Staniszewska, C. Marcinkiewicz and P. I. Lelkes, Endothelium, 2006, 13, 51-59.

28 G. E. Vargas, R. Vera Mesones, O. Bretcanu, J. M. Porto López, A. R. Boccaccini and A. Gorustovich, Acta Biomater., 2009, 5, 374-380.

29 M. Handel, T. R. Hammer, P. Nooeaid, A. R. Boccaccini and D. Hoefer, Tissue Eng., Part A, 2013, 19, 2703-2712.

30 A. Arkudas, A. Balzer, G. Buehrer, I. Arnold, A. Hoppe, R. Detsch, P. Newby, T. Fey, P. Greil, R. E. Horch, A. R. Boccaccini and U. Kneser, Tissue Eng., Part C, 2013, 19, 479-486.

31 H. Li and J. Chang, Acta Biomater., 2013, 9, 5379-5389.
32 H. Li, K. Xue, N. Kong, K. Liu and J. Chang, Biomaterials, 2014, 35, 3803-3818.

33 K. D. Lobel and L. L. Hench, J. Biomed. Mater. Res., 1998, 39, 575-579.

34 M. Park, Q. Li, N. Shcheynikov, W. Zeng and S. Muallem, Mol. Cell, 2004, 16, 331-341.

35 C. D. Hunt, J. Trace Elem. Med. Biol., 2012, 26, 157-160.

36 P. C. Brooks, R. A. Clark and D. A. Cheresh, Science, 1994, 264, 569-571.

37 R. A. Clark, M. G. Tonnesen, J. Gailit and D. A. Cheresh, Am. J. Pathol., 1996, 148, 1407-1421.

38 Y. Lin, R. F. Brown, S. B. Jung and D. E. Day, J. Biomed. Mater. Res., Part A, 2014, 102, 4491-4499. 